\title{
RENAISSANCE OF LIQUID CRYSTAL POLYMERS
}

\author{
Valeriy P. Shibaev
}

Lomonosov Moscow State University, Moscow, Russia

valeshib@mail.ru, https://orcid.org/0000-0002-8894-4211

\begin{abstract}
The paper consists of three interconnected parts. In the first part, the historical information about the initial works on the development of approaches for the creation of liquid crystal (LC) polymers is briefly considered. The results of the fundamental properties study of polymers carried out in the Laboratory of chemical transformations of polymers of the Chemistry Department at Moscow State University are presented. These polymers have been used as convenient matrices for creating of comb-shaped polymers by attaching mesogenic groups to their side branches (this is so-called a spacer concept). In the second part, some problems related to the priority of the original researchers worked in the field of LC polymers are analyzed in detail. The third part lists some promising areas that are developing in our LC Lab. Recent works relate to creation, study and possible application of new photo- and mechano-controlled LC polymers, di-and tri-block copolymers, as well as their composites with quantum dots for various applications in optics, optoelectronics and holography.

Key words: LC polymers, spacer, comb-shaped polymers, LC composites, triblock copolymers, quantum dots, photoorientation

For citation: Shibaev V.P. The renaissance of liquid crystal polymers. Liq. Cryst. and their Appl., 2021, 21 (4), 7-22. DOI: 10.18083/LCAppl.2021.4.7.
\end{abstract}

\section{Научная статья}

УДК 541.64:539(3+2)

РЕНЕССАНС ЖИДКОКРИСТАЛЛИЧЕСКИХ ПОЛИМЕРОВ

\section{Валерий Петрович Шибаев}

Московский государственный университет им. М.В. Ломоносова, Москва, Россия valeshib@mail.ru, https://orcid.org/0000-0002-8894-4211

\begin{abstract}
Аннотация. Представленная работа состоит из трех взаимосвязанных частей. В первой части коротко рассмотрены исторические сведения о первоначальных работах по разработке подходов $\kappa$ созданию жидкокристаллических (ЖК) полимеров. Приведены результаты исследований, проводимых в Лаборатории химических превращений полимеров Химического факультета МГУ, по изучению фундаментальных свойств гребнеобразных полимеров. Эти полимеры использованы в качестве матрии для создания ЖК-полимеров путем присоединения мезогенных групп к их боковым ответвлениям (так называемая концепция спейсера). Во второй части подробно проанализированы некоторые проблемы, относящиеся к приоритету первоначальных исследователей в области создания ЖК-полимеров. В третьей части статьи, в форме дайджеста, перечислены некоторые перспективные направления, развиваемые в университетской ЖК-группе. Эти работы связаны с созданием, изучением, а также возможным использованием новых фото- и механоуправляемых полимеров, двойных и тройных блок-сополимеров, а
\end{abstract}

(c) Shibaev V. P., 2021 
также ЖК-полимерных композитов с квантовыми точками для разнообразных применений в оптике, оптоэлектронике и голографии.

Ключевые слова: ЖК-полимеры, спейсер, гребнеобразные полимеры, ЖК-композиты, триблок сополимеры, квантовые точки, фотоориентация

Для цитирования: Shibaev V.P. The renaissance of liquid crystal polymers. Liq. Cryst. and their Appl., 2021, 21 (4), 7-22. DOI: 10.18083/LCAppl.2021.4.7.

\section{Some historical facts}

I would like to start this digest article with congratulations to the Editorial Board members of the «Liquid Crystals and their Application» Journal and its Editor-in-chief - Professor, Doctor of Chemical Sciences Nadezhda Vasilievna Usol'tseva.

Having headed in 1983 the Problem Laboratory of Liquid Crystals at Ivanovo State University, which was organized by Igor G. Chistjakov in 1976, N.V. Usol'tseva began actively study the issue of creating a new specialized journal dedicated to liquid crystals. Despite a significant number of works devoted to liquid crystalline (LC) topics and already carried out in the former Soviet Union, the results of these studies were mainly published in the Journal «Crystallography» founded by the Academy of Sciences of the USSR in the partnership with some universities.

Therefore, the Bureau of the Liquid Crystal Society «Sodruzhestvo» («Commonwealth») united liquid crystal scientists of the former republics of the Soviet Union, came to conclusion about the necessity to organize its own journal, in which the research results on LC state of matter would be published.

Unfortunately, the first attempts to publish printed collections, such as «Molecular Materials» (Moscow, Corporation MET, 1992) and «Liquid Crystals - Yesterday, Today and Tomorrow» did not stand the test of time and in several years they ceased to exist.

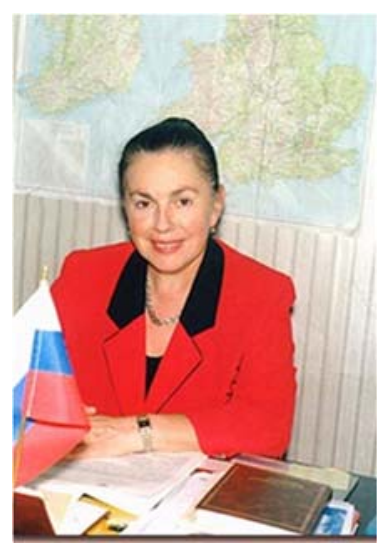

Fig. 1. Professor Nadezhda V. Usol'tseva
The main pioneer in this important business was Nadezhda Vasilievna Usol'tseva (Fig. 1), a professor at Ivanovo State University and a "successor" of the Ivanovo school of liquid crystals. Igor Grigorievich Chistyakov, who is one of the founders of liquid crystal studies in the USSR, and Valentina Alekseevna Usol'tseva (her mother) supervised her way to liquid crystal science.

At that time, N.V. Usol'tseva was a young and very energetic woman, already the head of the Problem Laboratory of Liquid Crystals at Ivanovo State University. She had an extensive experience in organizing AllUnion and International conferences dedicated to thermotropic and lyotropic liquid crystals. She has managed to convince the relevant State authorities and "break through" the permission to organize such journal.

Carefully selected members of the Editorial Board and the International Advisory Board, including wellknown scientists working in the liquid crystal field in in Russia and abroad, undoubtedly contributed to the influx of a large number of publications. All these contributed to the growth of scientific reputation, new publications and the consolidation of university and academic scientists, as well as research practitioners.

Although the first journal issues were only in black and white format and published in Russian, over time the journal acquired a modern scientific style and was included in the Scopus and Web of Science databases.

It is pleasant to note that our first scientific publications devoted to LC polymers were first reported at the First All-Union conference on liquid crystals in Ivanovo and published there as brief communications [1]. Moreover, it should be noted that the first reports, including a plenary lecture by V. Shibaev titled "Liquid Crystal Polymers", as well as the reports of his coauthors caused a very lively discussion of the conference participants, who "hostilely" accepted the basic concept of the work. What are LC polymers and, in general, is their existence possible in the sense that is used to define this term for lowmolecular-weight liquid crystals? These were the subject questions of the enough vivid discussion. 
Lyotropic liquid crystals have been known for a long time, and the original works of American and French scientists on the liquid crystal state of polypeptides and some viruses have been the subjects of many publications. In the early $70 \mathrm{~s}$ of the last century, the appearance of thermotropic LC polymers in the usual sense of this term raised many questions among the members of the LC community.

A little later, in 1975, on behalf of the university group, V.P. Shibaev presented a large report at the Mendeleev Congress on General and Applied Chemistry in Alma-Ata [2]. It should be noted that despite the large number of questions, the "polymer audience" was more loyal to a new term "thermotropic liquid crystal polymers". Most likely, it was due to the understanding of the polymer specificity of LC state of macromolecular compounds containing mesogenic groups. In 1977, in a large review in collaboration with N.A. Plate [3a], we summarized and presented the literature results and our own detailed studies on synthesis, structural features, phase behavior and physico-chemical properties of LC polymers. A year later, our article was published in the English version of the same Journal [3b].

The main idea underlying the creation of LC polymers was based on a set of works previously developed by us on the preparation of so-called combshaped polymers and study of their properties [4].

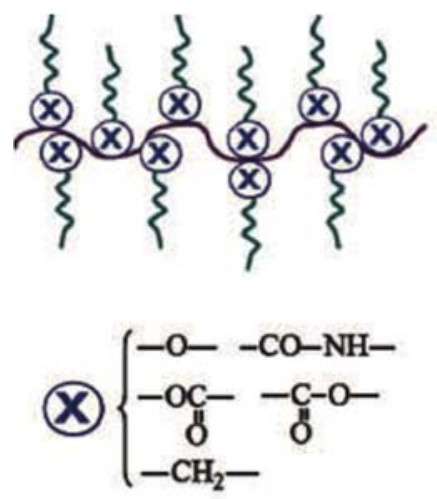

$a$

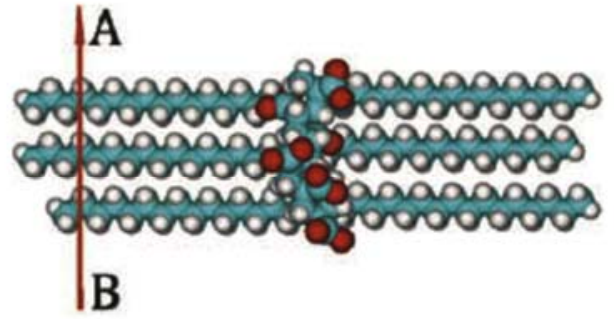

$b$

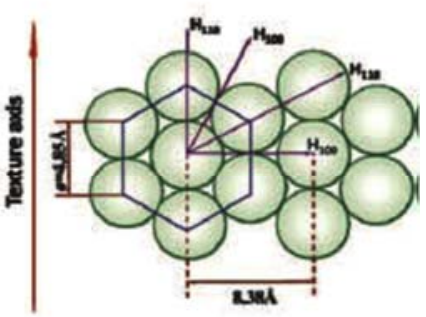

$c$

Fig. 2. Scheme of the molecular structure of a comb-shaped polymer $(a)$, molecular model of poly- $n$-hexadecyl acrylate $(b)$ and the side group packing of this polymer in hexagonal pattern in section $\mathrm{AB}(c)$

Fig. 2 shows a molecular model of one of these polymers consisting of two dissimilar elements - a main chain and long aliphatic branches [4]. These compounds include a wide range of poly- $n$-alkyl acrylates, poly- $n$-alkyl methacrylates, simple and complex poly$n$-alkyl vinyl ethers, and esters of poly- $n$-alkyloxiranes, etc. Our detailed studies of the structure of such polymers as well as copolymers allowed to draw an analogy with the structural organization of low-molecularweight liquid crystals forming a smectic phase [5-7]. In these early works based on our X-ray studies, it was shown that structure of comb-like polymers is characteristic of compounds in the so-called gas-crystalline state [8], which in turn is one of the varieties of liquid crystal state (Fig. 2, $a, b$ ). The side hydrocarbon chains of these polymers are considered in the form of rotating cylinders, the packing of which gives a hexagonal lattice in the plane perpendicular to the axis of the cyliners
(Fig. 2, c). The study of oriented samples of the combshaped polymers (poly- $n$-hexadecyl acrylate) and its gels in long-chain aliphatic alcohols and hydrocarbons showed that these compounds form liquid crystalline phases. Attaching significant importance to these comprehensive results, the authors published their data in the form of "a letter to the editorial board" in the Russian Journal "Polymer Science" in 1971 [9]. We quote: "Gels in alcohols, characterized by a layered structure, can be considered as smectic LC systems, and the absence of layer packing for hydrocarbon gels makes it possible to classify this structure as a nematic type of liquid crystals".

The specific dual structure of comb-shaped macromolecules, combining the mobility of side chains with their tendency to order, made it possible to use such polymers as self-organizing systems and convenient polymer matrices for the creation of $\mathrm{LC}$ 
polymers. They were called comb-shaped LC polymers (or side-chain liquid crystal polymers) and have proven to be excellent matrices for creating the first thermotropic LC polymers. In their macromolecules, side groups simulating mesogenic fragments of low-molecular-weight liquid crystals are linked to the main polymer chain by flexible (for example, aliphatic) decouples (spacers).

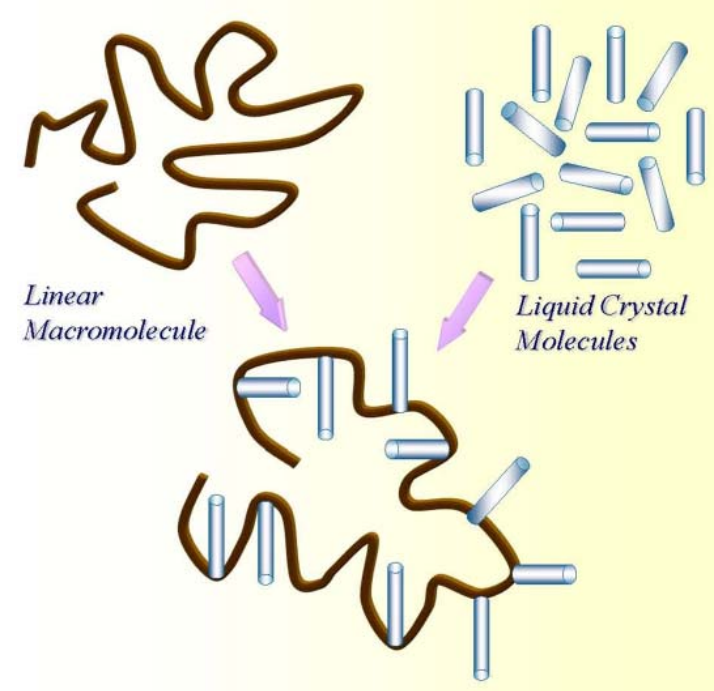

Direct attachment of mesogenic groups to the backbone does not usually lead to the formation of LC polymer. This is explained by steric hindrance imposed by the main chain on the mesogenic groups packing
It is important to note that earlier attempts to obtain LC polymers by covalent attachment of liquid crystals directly to the main chains of macromolecules turned to be untenable, and the resulting polymer compounds did not form a liquid crystal phase (Fig. 3). The detailed data on the problems of creating LC polymers are discussed in our monograph [10].

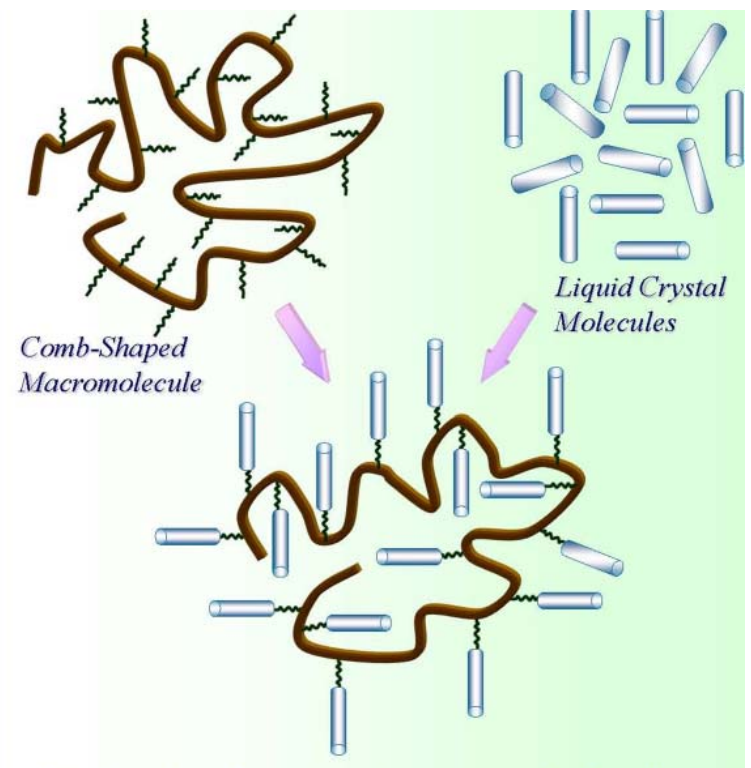

Attachment of mesogenic groups to backbone through the flexible spacer reduces steric restrictions upon the mesogenic groups packing. LC phases are being formed.

Fig. 3. Chemical linking of rigid liquid crystal molecules to flexible macromolecules

The spacer concept, first proposed and developed by us, played a decisive role in the creation of a new class of thermotropic LC polymers. The formulated principle of constructing macromolecular systems, which provides the possibility of synthesizing LC polymers with mesogenic groups in the side chains, consists in the chemical addition of mesogenic groups to the side aliphatic branches of comb-like polymers (Fig. 3). The preparation of such LC polymers is possible in two ways, as shown in Fig. 4. The method of polymerization and copolymerization is the most con- venient. Subsequently, more than a hundred different LC homo- and copolymers were synthesized using this approach [11]. It was also first used for synthesis of cholesterol-containing LC homo- and copolymers with smectic-type mesophases [11].

This approach has received further confirmation and development in numerous works of Russian, German, English, French and other researchers. Today it is a generally accepted method for obtaining thermotropic liquid crystals polymers with side mesogenic groups (comb-shaped LC polymers). 

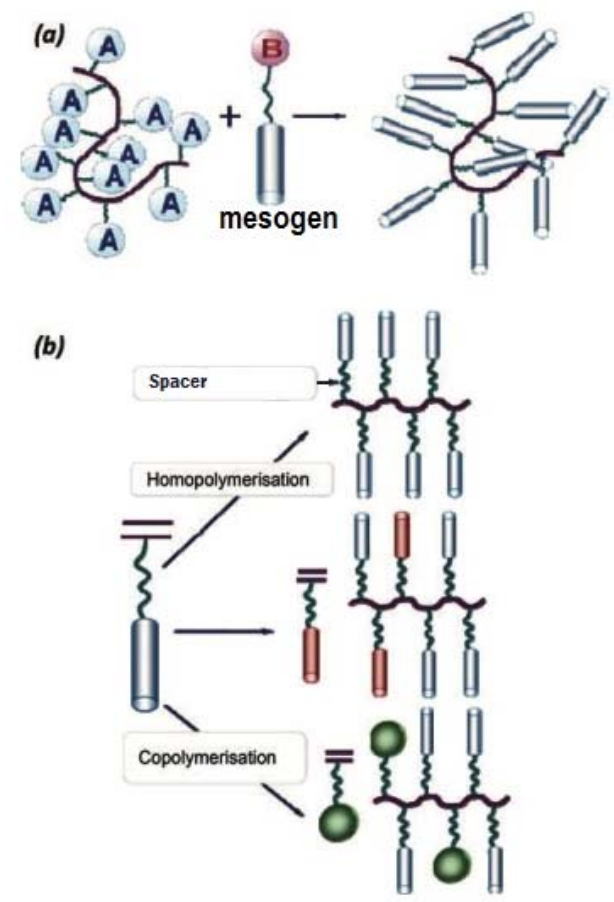

Fig. 4. Two synthesis methods of comb-shaped polymers: $a$ - polymer analogous reaction of the comb-shaped polymer containing functional groups $\mathbf{A}$ with mesogenic fragments containing functional groups $\mathbf{B} ; b-$ homo- and copolymerisation of mesogenic monomers with mesogenic and non-mesogenic monomers

\section{Priority issues}

Considering the issue of research priority in LC polymers, it should be emphasized that the first works on the synthesis of "comb-shaped LC polymers" (as mentioned above) were presented at Russian conferences in 1974-1975 [1-2]. In 1975, we received a Russian patent for the invention of a method for producing a LC polymer [6]. In 1977, in the Russian Journal, we published the first comprehensive review - "Liquid Crystal Polymers" [3a]. For the first time, in this paper, the so-called "spacer concept" was described in detail, along with the synthesis and properties of the number of new comb-shaped LC polymers. One year later, in 1978, the paper was translated into English and published in the journal "Polymer Science USSR" [3b].

In the same year (1978), the journal Die Macromoleculare Chemie published a research work of German scientists (H. Finkelmann, H. Ringsdorf and J. Wendorff, Fig. 5) [13]. The authors also proposed to use the spacer concept for obtaining liquid crystal polymers, which were called "side chain liquid crystal polymers". It is important to note that in ACS Symphosium Series, the "Mesomorphic Order in Polymers" collection, in which German [13] and our [14] articles were published, the German authors refer to our works from 1976-1977.

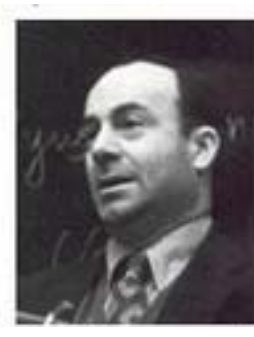

N. Plate

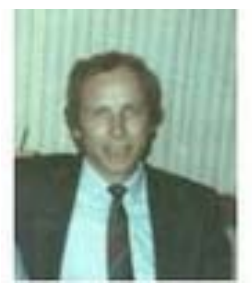

H. Finkelmann

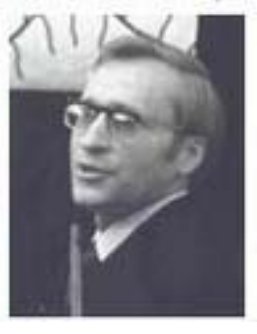

V. Shibaev

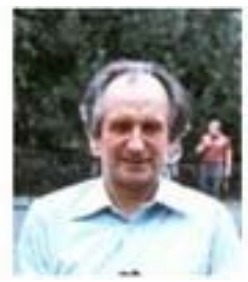

H. Ringsdorf

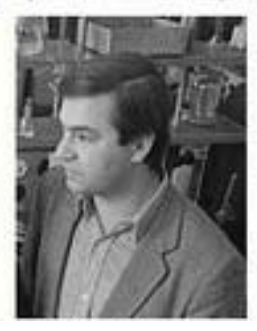

Ya. Freidson

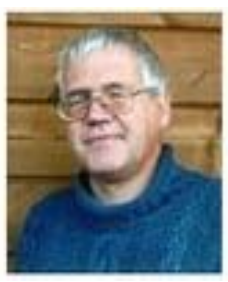

J. Wendorff
Fig. 5. Authors of first publications on the synthesis of thermotropic LC polymers with side chain mesogenic groups (comb-shaped LC polymers) based on the "spacer concept"

Fig. 5 shows the photographs of Russian and German researchers, who almost simultaneously published works related to the synthesis of LC thermotropic polymers based on the spacer concept. However, without going further into the details of the priority nature of the work related to the synthesis of thermotropic LC polymers, we would like to note only one circumstance.

In 2004, the book Crystals That Flow: Classic Papers from the History of Liquid Crystals [15] was published by eminent scientists and devoted to the history of discoveries in liquid crystals. This comprehensive monograph describes the most significant successes in the study of low molecular weight liquid crystals from the historical point of view, including Russian scientists (Tsvetkov V.N. and Chistyakov I.G.). However, for some reason, the works devoted to the creation of thermotropic LC polymers were omitted. 
At the same time, in the 1970's, the first works on the development of approaches for obtaining LC polymers were published by American scientists under the leadership of A. Blumstein [16-17], French researcher L. Strzelecki et al. [18], and a Hungarian group of coauthors (G. Hardy, K. Nuitrai, F. Cser) [19]. Other interesting approaches to the creation of LC polymers were not even cited: see for example, the book Chemistry of Liquid Crystals and Mesomorphic Polymer Systems by Soviet scientists Y. Amerik and B. Krentsel [20]. In these publications [16-20], the approaches are based on the unrealized idea of polymerization of monomers in organized anisotropic (i.e. LC) media that would have led to the formation of polymers with an ordered molecular and supramolecular structure.

We would like to remind that our "spacer concept" was presented in our review in the Russian Journal [3a].

In 1980, all these issues were presented in detail in our monograph "Comb-shaped Polymers and Liquid Crystals" published in Russian [10a] and then, its significantly expanded English version was printed by Plenum Press in 1987 [10b].

By the time when the Crystals That Flow monograph was in print [16], several of our major scientific publications had already existed, including the reports from our Moscow University group at International conferences. The author of this article for his significant contribution to the synthesis and research of thermotropic polymer liquid crystals was included in the editorial board of the new International Journal "Liquid Crystals" by invitation of G. Luckhurst and ed. Samulsky. In addition, attaching great importance to the creation of a new class of LC compounds (namely LC polymers), the International LC Society organized the first International Conference exclusively devoted to LC polymers, which took place in 1978 in Bordeaux (France) (Fig. 6) [21]. V.P. Shibaev was invited to give a large talk, which was published later in the special issue titled "New Liquid Crystalline Materials" of the "Molecular Crystals and Liquid Crystals" journal [22].

The conference was a great success and brought together more than 200 participants not only from academic and university organizations, but also from large foreign companies interested in the practical use of these new materials.

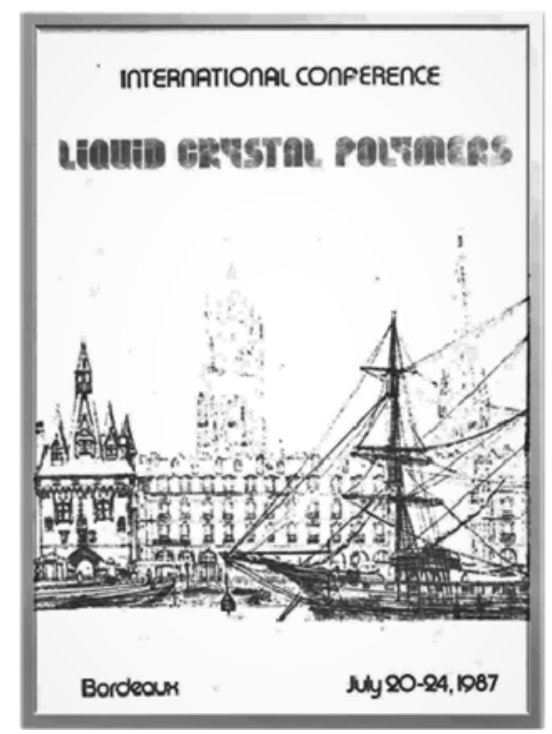

Fig. 6. The Program and abstracts cover of the International Conference on "Liquid Crystal Polymers", that took place on July 20-24, 1987 in Bordeux, France

In 1989, the reports of invited speakers were collected in the book Side Chain Liquid Crystal Polymers published under the editorship of C.B. McArdle (Loctite Ireland, Ltd, Dublin) [23a]. This book was translated into Russian [23b] under the editorship of the author of this article. For scientific achievements, five conference participants - A. Windle (UK), A. Blumstein (USA), F. Laupretre (France), V. Shibaev (USSR), and H. Ringsdorf (Germany) - were elected as Honorary citizens of the famous St. Emilion region, where the conference was held (Fig. 7).

The successes in the use of main and side chain LC polymers and their composites were also discussed at the International Conference in Beijing in 1994, where both Russian (V.P. Shibaev, N.A. Plate) and German (H. Finkelmann, J. Wendorff) scientists presented their invited talks. Interesting reports related to LC polymers were also presented by C. Noel (France), J. Galli (Italy), and a number of Chinese scientists. 

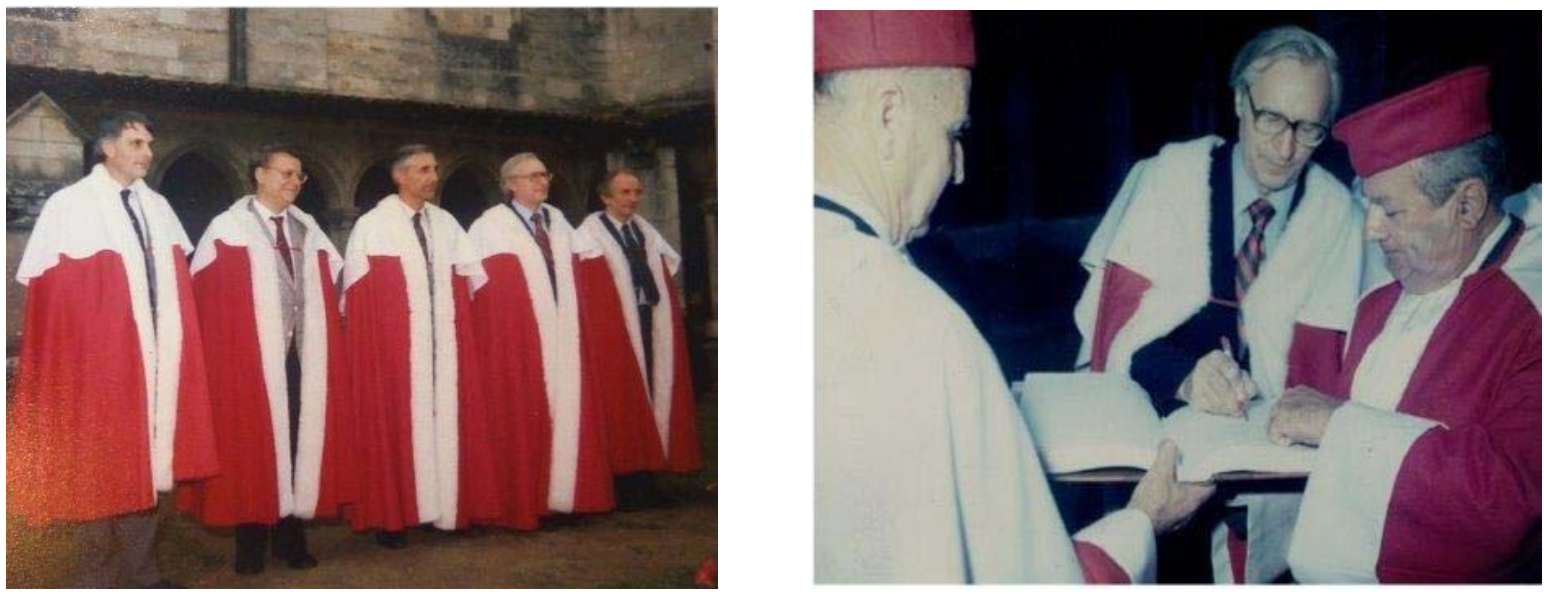

Fig. 7. Five Honorary Citizens awarded with diplomas of the Saint-Emilion province (France). (From left to righ: A. Windle, A. Blumstein, F. Laupretre, V. Shibaev, H. Ringsdorf). Presentation of the diploma to Prof. V.P. Shibaev

Nevertheless, in publications devoted to LC polymers with mesogenic side groups, the authors [15] refer only to $[12-13]$ as the "primary source" of works on LC polymer creation. This disregard of our works could be explained by difficulties in translating Russian-language publications into English in the seventies. However, a huge time gap between the indicated late-seventies works stating the Russian priority and the "historical monograph" [15] published in 2004 indicates the insufficiently careful acquaintance and assessment of Russian (Soviet) scientists' works.

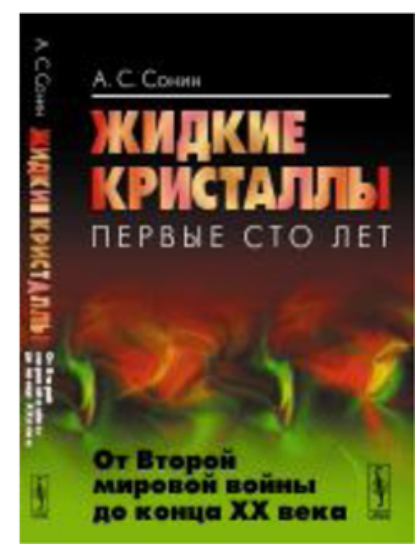

Fig. 8. The cover of A.A. Sonin "Liquid Crystals", 2015, Volume 2 [24]

The most objective and comprehensive historical information is presented in the extensive two-volume monograph written by one of the leading scientists in the physics of liquid crystals - Doctor of Chemical and
Physical and Mathematical Sciences, Prof. A.S. Sonin (Fig. 8) [24]. The author examines in detail a series of works performed by the researchers from Moscow State University under the leadership of Plate-Shibaev, noting their priority not only in the development of approaches to the creation of LC comb-shaped polymers, but also in the study of their behavior in electric and magnetic fields, the preparation of LC gels, cholesteric and ferroelectric LCs polymers (Ja. Freidzon, R. Talrose, S. Kostromin, N. Boiko, M. Kozlovsky et. al).

This is where we will probably end the consideration of issues on the priority nature, caused mainly by the non-objectivity of the information presented in [15]. However, it is pleasant to note that our German colleagues, just like our Moscow researchers, have never been engaged in clarifying these priority problems among themselves and have always kept friendly relations.

During X. Ringsdorf's visit to Moscow in 1977, he invited V.P. Shibaev to work for a couple of months in his laboratory at the Institute of Organic Chemistry at the University of Mainz, Germany. This visit turned out to be very fruitful: using German acrylic nematic monomers and Russian cholesterol-containing monomer synthesized by us at Moscow State University, we (together with Dr. Heino Finkelmann) synthesized the "first cholesteric Russian-German copolymer". After the return of V.P. Shibaev to Moscow and upon completion of this work we published a joint article [25]. Subsequently, we maintained friendly relations with colleagues from Mainz and welcomed them with cordiality in Moscow. (Fig. 9, 10). 


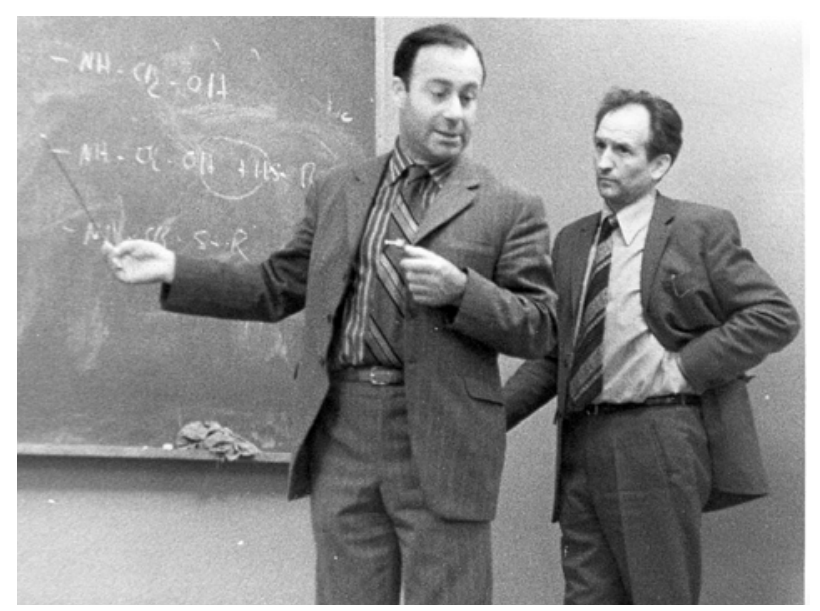

Fig. 9. Prof. X. Ringsdof and Prof. N. Plate are discussing some problems relating to LC topics at the Polymer

Division of Moscow State University in 1977

The end of the seventies and the eighties of the last century should be called the period of the "liquid crystal boom". Hundreds of new LC polymers exhibiting the properties of cholesteric, nematic, and smectic types of mesophases were obtained in different countries, methods for controlling their structure and properties using external electric and magnetic fields were developed, and LC polymer ferroelectrics and piezoelectrics were synthesized.

The "spacer concept", which works perfectly for the production of LC homopolymers, happened to be very convenient for the production of more complex systems: multifunctional LC copolymers, LC dendrimers, and LC ionomers. The first photochromic representatives of such systems were described by us in a review [26] together with A. Bobrovsky and N. Boiko. This work marked the beginning of a new active direction associated with the creation of photochromic and multifunctional LC polymer systems.

An example of such a hypothetical macromolecule is shown in Fig. 11, where a variety of functional groups can be simultaneously present. Mesogenic groups can carry photochromic, electroactive, chiral and other mesogenic and non-mesogenic fragments. As non-mesogenic branchings, the side groups can include ionogenic fragments bearing positive or negative charges, as well as nanoparticles directly linked to the main chain or attached through a spacer.

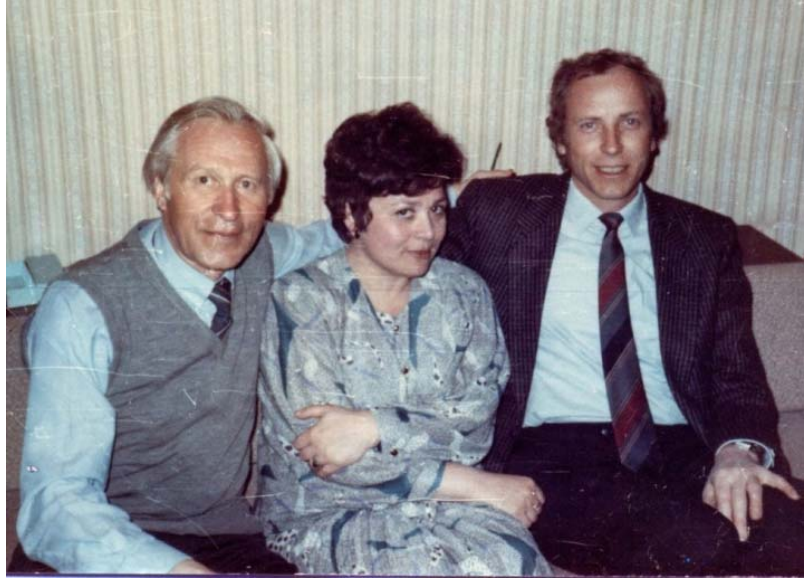

Fig. 10. Prof. V. Shibaev (Russia), Prof. R. Talrose (Russia) and Prof. H. Finkelmann (Germany) in Moscow

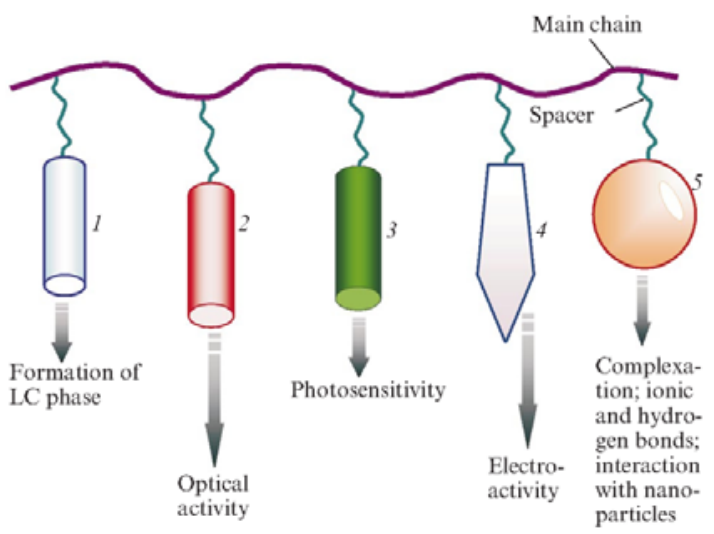

Fig. 11. Schematic representation of a macromolecule of multifunctional comb-shaped copolymer

It was shown that for manifestation of liquidcrystalline properties, multifunctional polymer systems must contain at least $30-35 \%$ of mesogenic groups capable of self-organization and mesophase formation.

Figure 12 illustrates special properties of these LC systems. As follows from Fig. 12, the LC state of polymers is realized in the temperature range between glass transition temperature $\left(\mathrm{T}_{\mathrm{g}}\right.$ ) (or melting point temperature if a polymer is able to crystallize) and isotropization temperature ( $\left.\mathrm{T}_{\text {Iso }}\right)$, above which a polymer loses its LC properties and transforms into an isotropic melt. 
Within this temperature range $\left(\mathrm{T}_{\mathrm{g}}-\mathrm{T}_{\text {Iso }}\right)$, LC polymer behaves similarly to low-molecular-weight liquid crystals, producing nematic, smectic, or cholesteric phases, and can be easily subjected to the action of external fields (mechanical, electric, or magnetic). A unique feature of LC polymers is that after cooling below $\mathrm{T}_{\mathrm{g}}$, they preserve the "frozen" structure inherent to the abovementioned phases and, together with anisotropic properties, which are either characteristic of the initial mesophase structure or induced by the action of external field.

Therefore, the possibility to fix anisotropic structure of mesophase in a solid state preserving unique optical properties of LC polymers offers great and fascinating opportunities for the development of new innovative materials with unique adjustable optical as well as other physicochemical and mechanical properties [27].

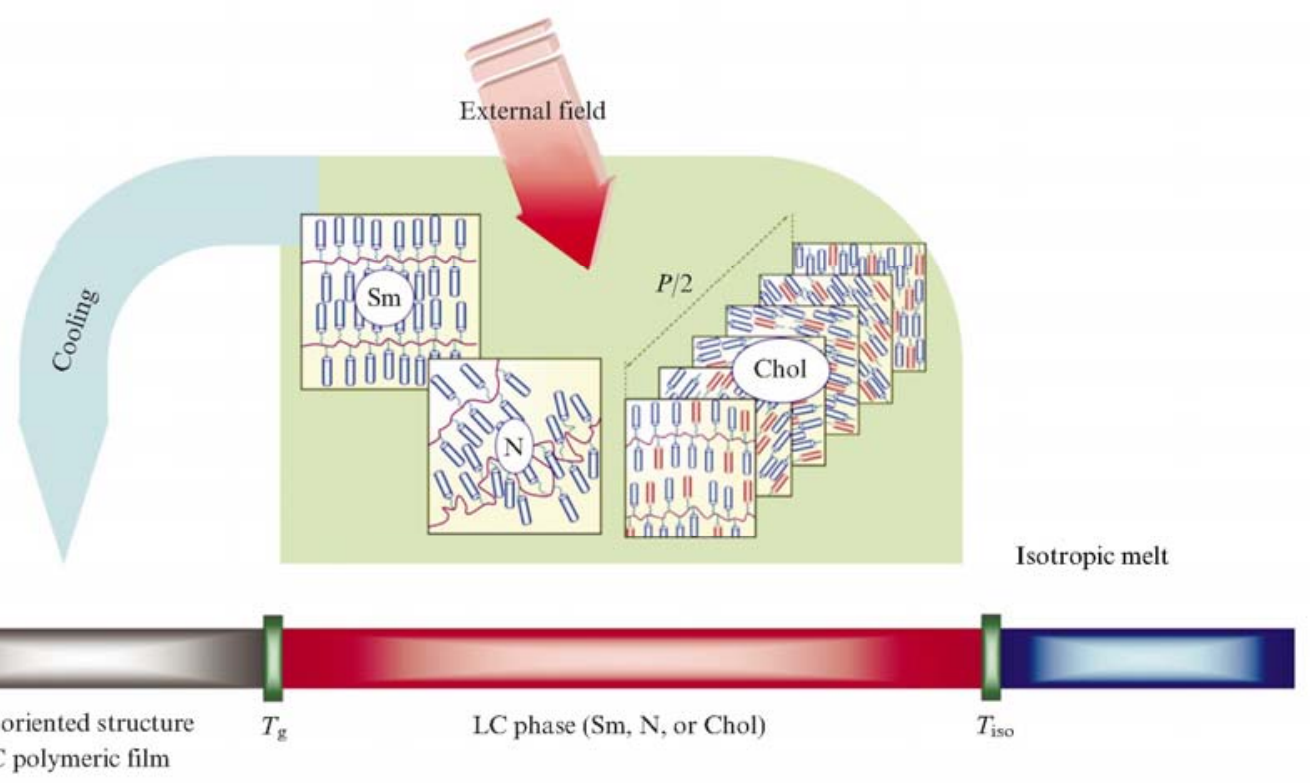

Fig. 12. Scheme illustrates the existence of regions of various types of mesophases of the LC polymer and their possible stabilization (freezing) with a given molecular orientation upon cooling or under the action of external fields

The presence of various functional groups in the side branches of monomeric units of comb-shaped macromolecules in combination with different mesophases formed by them ( $\mathrm{Sm}, \mathrm{N}$, Chol) opens unlimited possibilities for creating new types of functionally integrated hierarchical supramolecular structures. Such LC systems should be regarded as a fascinating and delicate "soft matter", on the basis of which new smart and intellectual materials can be elaborated.

\section{Digest of some results obtained in LC Shibaev's group at Moscow State University}

The main focus of our recent research is the development and study of the properties of "smart" stimulus-sensitive LC polymer materials. These types of LC materials include photochromic, electrosensitive, fluorescent polymer systems, nonlinear optical compounds, ionogenic and ionophore polymers as well as photo- and thermosensitive LC gels.

An excellent combination of physicomechanical properties of polymers (the ability to produce stable films, fibres, and thin-film coatings) and the unique optical characteristics of liquid crystals attract researchers to create new types of "soft matter LC materials".

Light-sensitive LC polymers are of particular interest because light offers a pure and non-contact method of controlling optical properties of the LC materials with high spatial and temporal resolution.

Fig. 13 demonstrates different types of homoand copolymers containing mesogenic and photochromic groups, which have been synthesized in our laboratory. In addition to mesogenic and photochromic moieties, LC copolymers may contain chiral side groups 
incorporated in copolymer as individual monomer units. Chiral and photochromic moieties can also be integrated in one monomer unit. Besides, LC copolymers can have photochromic banana-shaped and ionophoric groups, which are capable of complexation with metal species. A special type of LC compounds are binary and ternary block copolymers with different subblocks. Recently, cross-linked LC polymeric networks and LC composites attract a special interest (Fig. 14).

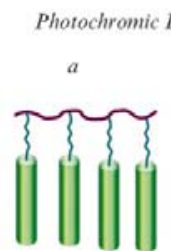

Homopolymer polymers

$b$

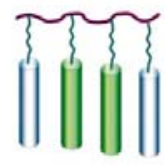

Copolymer

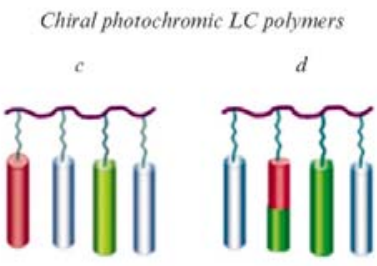

Block copolymers

Ionophoric LC polymers

$g$

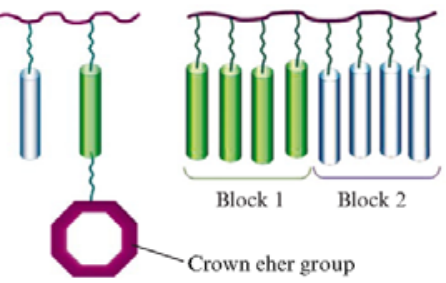

LC networks
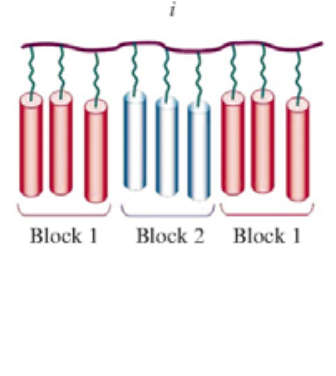

1

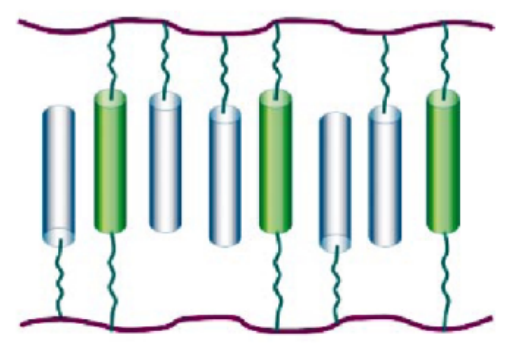

Banana-shaped LC polymers

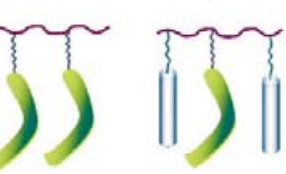

Homopolymer Copolymer

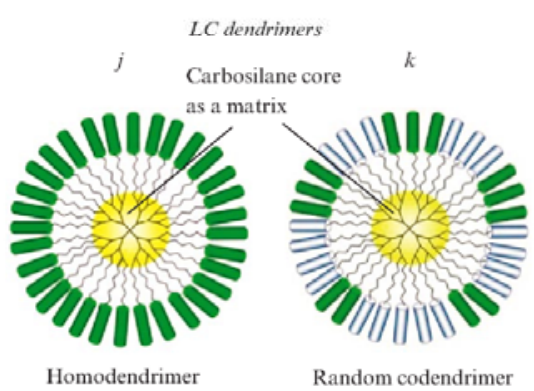

Fig. 13. Photochromic comb-shaped LC polymers and LC dendrimers with diverse structures

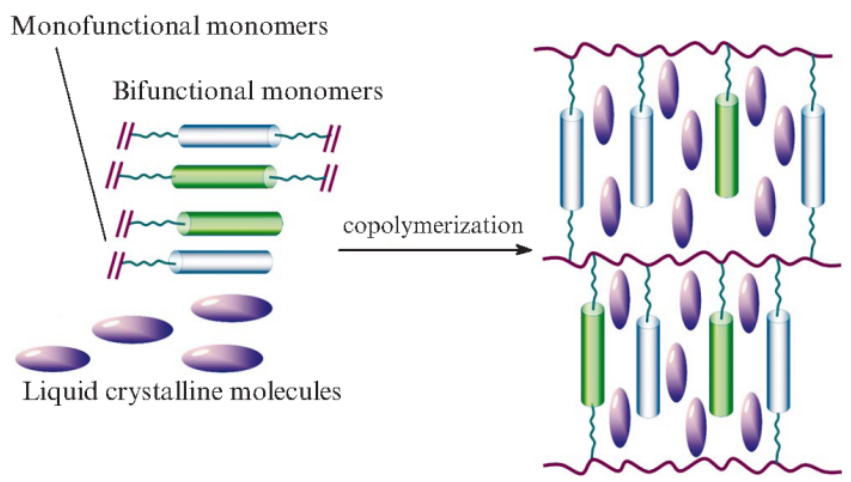

Fig. 14. The pathways to photochromic LC polymer networks and related composites by copolymerization of mono- and bifunctional monomers in the presence of liquid crystals 


\subsection{Photoorientation of photochromic LC polymers: photorecording, photopatterning and creating command surfaces (films)}

The presence of photochromic side groups in the comb-shaped LC polymers and copolymers determines their ability to E-Z-isomerization under the action of polarized light. This process is accompanied by cooperative orientation of photochromic and non-

a)

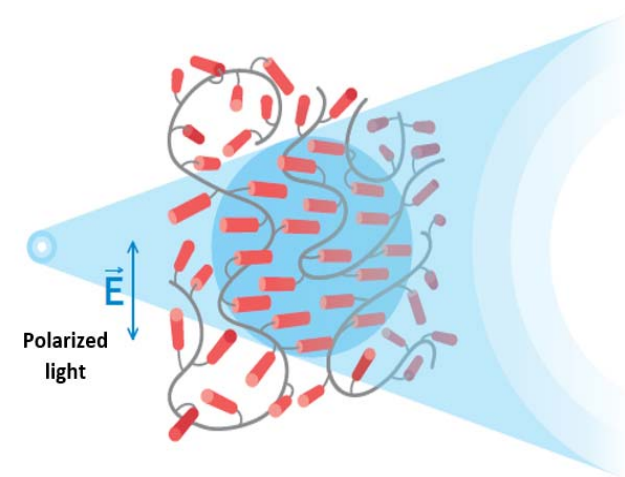

c)

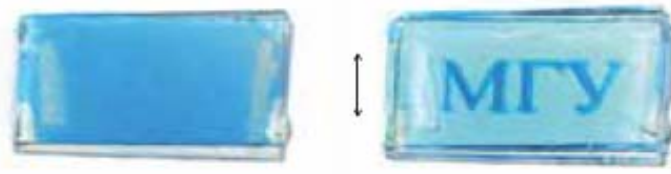

photochromic groups [26-28]. The result of the process is the appearance of dichroism and birefringence, which can be used for local recording of images and information (Fig. 15). Thin films of LC polymers with latent images can be used as transparent optical elements for anticounterfeit production and verification of the authenticity of some objects-copyprotecting banknotes, securities and identity cards [28-30].

b)

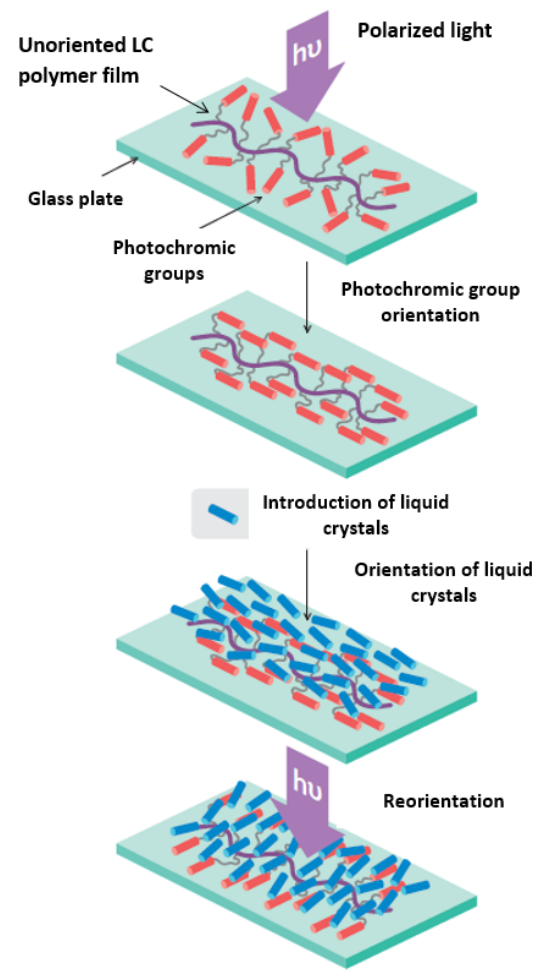

Fig. 15: $a$ - Photochromic group orientation under the action of polarized light. $b$-Successive steps of orientation and reorientation of photochromic groups of LC polymers and liquid crystals. $c$ - Latent image of a LC cell recorded with polarized light viewed without (left) and with (right) polarizer

\subsection{Modification of surface properties of $L C$ polymer films and photoregulation of their topography}

The possibility of obtaining polymer films with a "frozen" LC structure (Fig. 16) opens up unusual ways of creating micro- or nano-surface relief on LC films. This is most pronounced for LC polymers with cholesteric structure, containing a small concentration of azo- benzene chiral photochromes (with left- or righthanded dopants). Fig. 16 demonstrates a typical set of fingerprint confocal domains. The UV-illumination of the film caused changes in the twisting power of the photochromic dopants, which manifested either in increase or in decrease of the helix pitch size of confocal "domains". A comparison of $(a)$ and $(b)$ of Fig. 16 shows that the average period of domain surface relief changes from 570 to $350 \mathrm{~nm}$ [31]. 


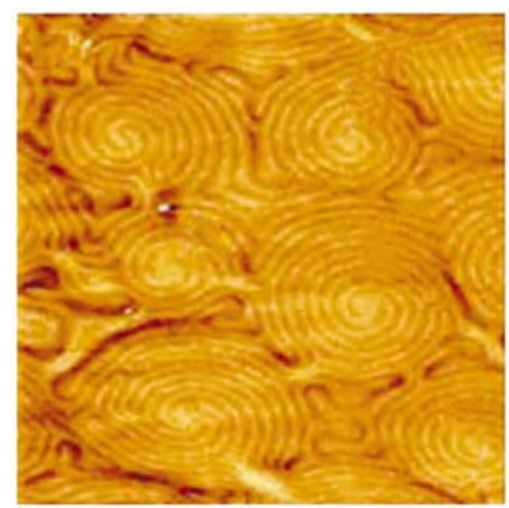

$a$

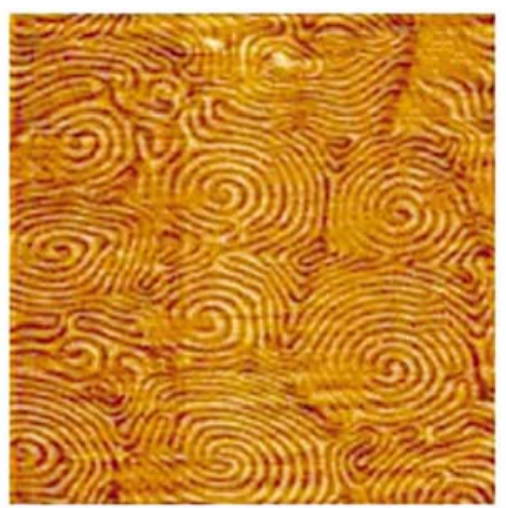

$b$

Fig. 16. Microphotographs of the initial cholesteric film surface with a small concentration of photochromic dopant at room temperature $(a)$ and the same sample after UV illumination and annealing $(b)$

The recent studies on the effect of highly focused green $(\lambda=532 \mathrm{~nm})$ and red light $(\lambda=633 \mathrm{~nm})$ laser beams on the surface topography of LC polymer films attract a special interest. Fig. 17 shows AFM images of the surface of cyclosiloxane cholesteric film with a dopant. Under the action of well-focused green beam, a so-called "crater-like" structure is formed. While under the action of red laser, a so-called "hill-like" structure is formed. The reason for this behavior of the same polymer under the action of green and red lasers is still unknown and we are trying to find an explanation for this phenomenon [32].

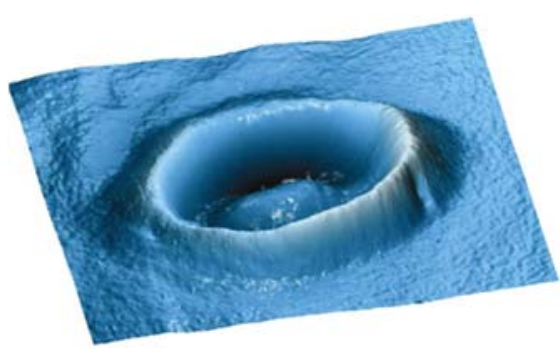

$a$

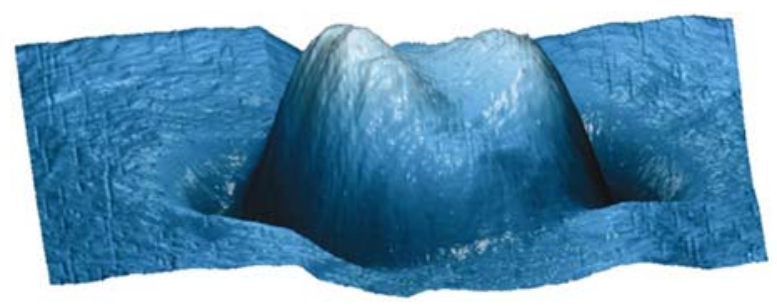

$b$

Fig. 17. Surface structures produced under the action of a well-focused green $(a)$ and red light $(b)$ on the film of polymer

\subsection{Mechanosensitive polymer-dispersed cholesteric liquid crystals on the base of polymer elastomers}

The combination of good mechanical properties of elastomers and the unique optical properties of liquid crystals opens up opportunities for the production of novel optical materials with controlled optical properties under the action of mechanical deformation.

For preparation and study of optical properties of polymer-dispersed cholesteric liquid crystals based on polysiloxane and polyurethane elastomers (PDLC elastomers) we developed special methods.

The stretching of PDLC elastomers results in shifting of the selective light reflection peaks to the short-wavelength spectral region. The amplitude of the shift depends on the stretching degree and reaches more than $100 \mathrm{~nm}$ (Fig. 18, 19) [33].

The obtained polymer composites are promising for creation optomechanical tensile and deformation sensors. 


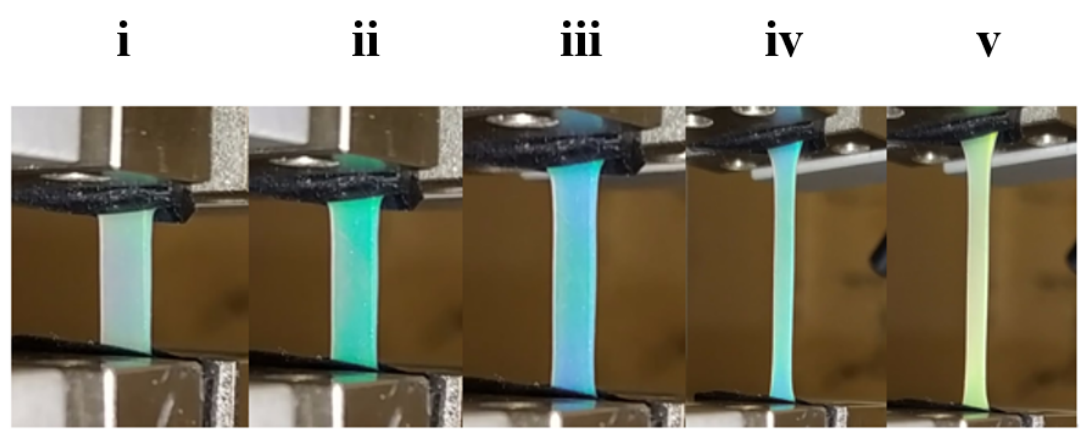

Fig. 18. Photos of deformable polyurethane composite during stretching: i) initial, ii-iv) elongation up to $150 \%$, v) 3 seconds after fixation

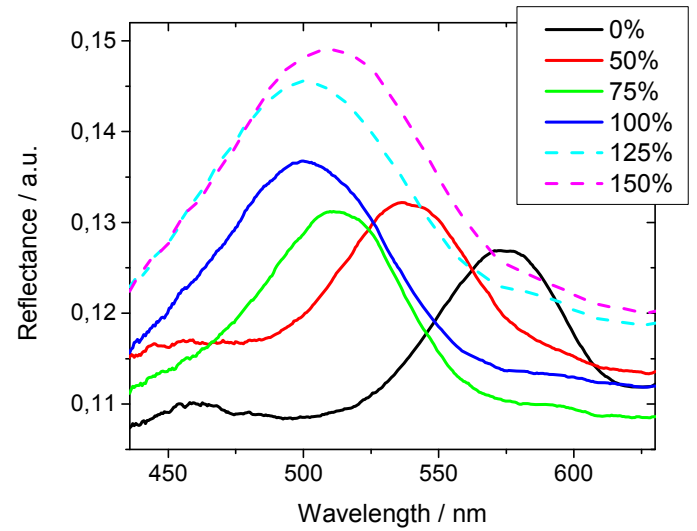

Fig. 19. Reflectance of the PDLC elastomer sample during stretching. The insert notes the stretching degree of the elastomer

\subsection{Stimulus-sensitive LC complexes of triblock copolymer films for photonics}

Macromolecular structure of block-copolymers, consisting of alternating blocks of different components opens an unlimited number of various combinations for design of block-copolymers with different architecture.

We have developed an original approach by synthesizing new "hybrid" regular triblock copolymers of $\mathrm{A}_{n} \mathrm{~B}_{\mathrm{m}} \mathrm{A}_{\mathrm{n}}$ type, consisting of LC comb-shaped polyacrylate with side phenyl benzoate monomer units (block $\mathrm{B}_{\mathrm{m}}$ ) and amorphous linear polyvinylpyridine (PVP) block. The amorphous PVP "tails" (that is blocks of $A_{n}$ type) were used to "load" them with photochromic compounds. The peripheral blocks of PVP serve as templates, the monomer units of which can be connected with azo-containing chromophores by hydrogen bonds (Fig. 20). In such a way a new hybrid LC supramolecular complex is formed, having a central comb-shaped LC block bordered on both sides by the blocks of PVP complexes with azo-benzene photochromes. The composition of the complexes is easy to control by changing their content [34].

Combination of LC properties and photochromism of the complexes of block copolymers made it possible to use them for obtaining new photoactive media and photooptical materials. Irradiation of block-copo-lymers films with hydrogen-bonded chromophores with linearly polarized light causes reversible cyclic processes of trans-cis-trans isomerization of azobenzene-containing groups, which leads to the orientation of chromophores. It is important to emphasize that mesogenic phenyl benzoate groups of the LC subblock are additionally involved in this photoorientation process, which is accompanied by the appearance of birefringence and optical dichroism. In other words, it becomes possible to locally change the optical properties of polymer films under the influence of polarized light and use these processes for recording and storing information.

However, despite the excellent quality and high resolution of the irradiated samples, they have a yellow color due to the presence of azobenzene chromophores. This fact makes the irradiated films not stable enough. An example of a polymer film with a recorded test lattice is shown in Fig. 20, (4).

At the same time a remarkable property of such complexes is the ability to remove hydrogen-bonded chromophores under the action of a selective solvent. Extraction of azo-benzene from a film of block copolymer complexes with recorded information make possible a complete removal of photochromic groups and obtaining colorless and transparent polymer films. 


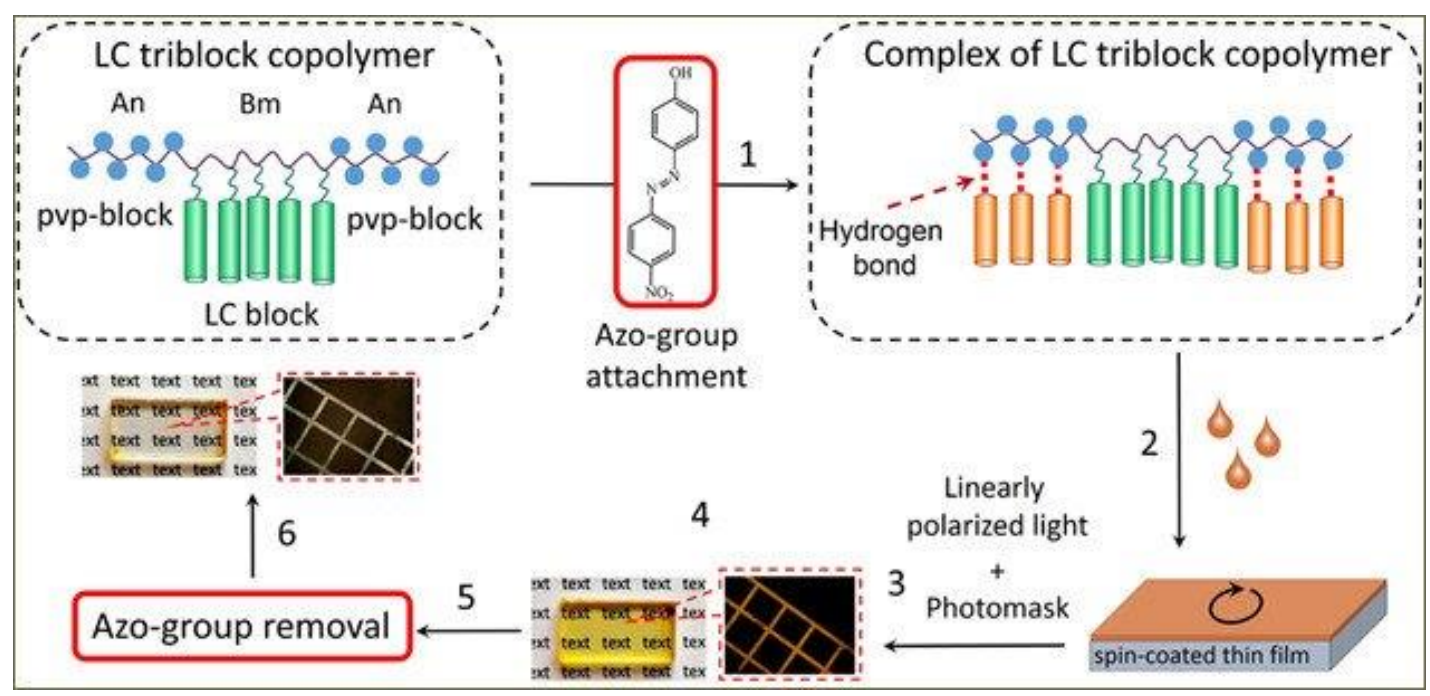

Fig. 20. Sheme for the synthesis of a complex of LC triblock copolymers (1), obtaining a film from a solution by spin-coating (2), irradiation of a film with linearly polarized light through a mask (3), image of a film with a recorded test-grating (4), removal of azophotochrome (5), obtaining a transparent and colorless film (6)

Image retention is determined by the present photoorientation of lateral mesogenic phenyl benzoate groups during preliminary irradiation of the film and associated with modulation of the refractive index. Hydrogen-bonded photochromic groups play their initiating role in the form of a "seed" for recording information, but already on a colorless and transparent polymer.

This new and rather elegant approach for the preparation of supramolecular linear-comb-shaped LC triblock copolymers with hydrogen-bonded photochromic fragments and their subsequent removal can be considered as a new basis for production of new photoactive materials for optical recording, storage, and display of optical information.

The photochromic complexes of linear-combshaped LC triblock copolymers introduced in this sec- tion serve as a prime example of new types of polymer materials for molecular design and the creation of transparent polymer films with high image stability in the absence of photochromes.

\subsection{Hybrid fluorescent $L C$ composites based on $L C$ block copolymers with quantum dots}

Hybrid fluorescent LC composites containing inorganic quantum clots (QDs) are promising materials for many applications in optics, nanophotonics, and display technology. However, the compatibility of QDs and organic LC matrix is a considerable challenge in creating theыe composites.

We have developed an approach to prepare hybrid LC composites with rather high (10-15 wt. \%) loading of CdSe/ZnS QDs (Fig. 21) [35].

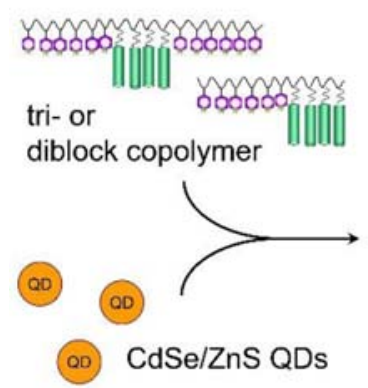

\section{LC polymer-QD composite}

(I)

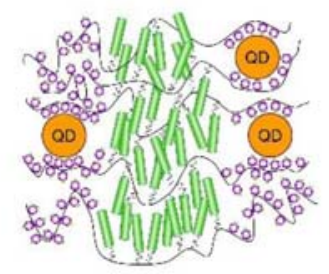

QDs decorated with LC block copolymer and introduced into low-molecular-weight LC

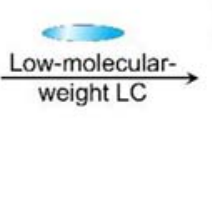

(II)

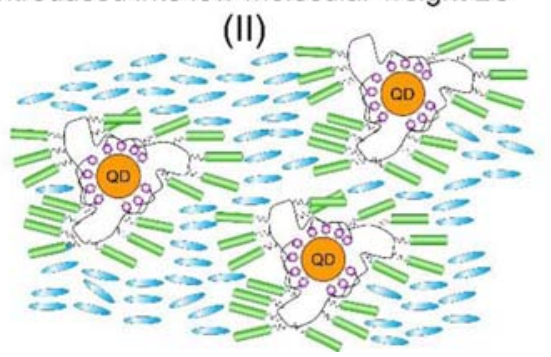

Fig. 21. Preparation route of the hybrid LC composites doped with CdSe/ZnS QDs 
The approach is based on LC tri- or diblock copolymers containing phenyl benzoate nematic combshaped LC block and polyvinylpyridine blocks, which are capable of forming coordinate bonds with the surface of QDs. We demonstrate two ways to use these block copolymers: i) as a nematic polymer matrix, or ii) as a compatibilizer between QDs and low-molecular weight cholesteric liquid crystals.

The resulting composites are dissolved in a cholesteric LC mixtures for obtaining a LC system with uniformly distributed QDs, where the LC block copolymer acts as a highly efficient compatibilizer.

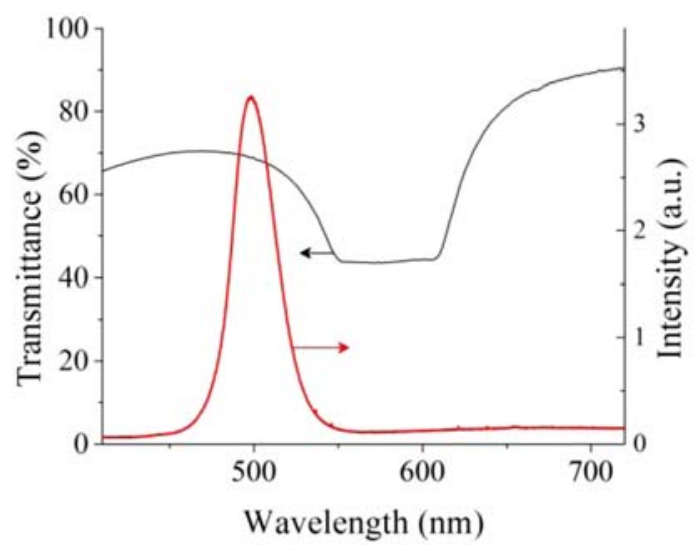

Fig. 22. Absorbance and fluorescence spectra of the hybrid cholesteric composite containing $5 \mathrm{wt}$ \% of QDs

Due to well-organized structure of the diblock copolymers, QDs are arranged in either lamellar or cylindrical arrays. All composite films under irradiation with blue laser $(\lambda=473 \mathrm{~nm})$ demonstrate bright light/emission due to the presence of QDs (Fig. 22).

The obtained composites seem to be not only the good compatibilizers for LC organic compounds and inorganic QDs, but a convential route for the design of highly ordered hierarchical hybrid materials for optical applications and fundamental research.

\section{Instead of conclusion}

Since this article is limited in scope, we could not consider other interesting examples of stimulus sensitive LC polymers, such as electro and magneto-sensitive materials, photo actuators, LC composites, crosslimited LC networks, etc. In any case, this interesting area of a new type of "soft matter" undoubtedly requires active attention and development of the chemical, physical, and biological research profile. In this anniversary year of the Journal we would like to wish its Editorial
Board and staff great success in the future of developing this interesting and mysterious LC field of research.

Acknowledgements: The author express their deep gratitude to their colleagues Prof. A.Yu. Bobrovsky, Prof. N.I. Boiko, Dr. M.A. Bugakov, Dr. A.V. Ryabchun, Ph.D. student N.V. Balenko for cooperation and their publications, which were cited in this article and to O.G. Antokhina for the computer-aided preparation of the manuscript. This paper was prepared with the financial support of the Russian Science Foundation Project (№ 19-13-00029).

\section{References}

1. Freidzon Ya.S., Shibaev V.P., Plate N.A. Liquid crystalline state some comb-shaped liquid crystal polymers. Abstracts of the 3rd All-Union conference on liquid crystals. Ivanovo, 1974, 214-215. (in Russ.).

2. Shibaev V.P., Freidzon Ya.S., Plate N.A. Structure formation in comb-shaped polymers. Abstracts the 11-th Mendeleev Congress on General and Applied Chemistry. Alma-Ata, 1975, 2, 164. (in Russ.).

3. Shibaev V.P., Plate N.A. Liquid crystalline polymers. Vysokomol. Soed., 1977, A19, 923-972 (in Russ.) (a); Shibaev V.P., Plate N.A. Liquid Crystalline Polymers. Polymer Science USSR, 1978, A19, 1067-4122. (in English) (b).

4. Plate N.A., Shibaev V.P. Comb-shaped polymers: structure and properties. J. Polymer Sci.: Macromolecular Reviews, 1974, 8, 117-253.

5. Shibaev V., Petrukhin B., Zubov Yu., Plate N., Kargin V. Influence of side chain length on crystallization and structure-formation. Vysokomol. Soed., 1968, 10A, 216-226 (in Russ.).

6. Inventer’s Certificate № 525709 USSR. Method of obtaining polymers / Shibaev V.P., Freidzon Ya.S., Plate N.A.; Bull. № 31; 1976. Right holder: Faculty of Chemistry, Moscow State University.

7. Shibaev V.P., Freidzon Ya.S., Plate N.A. Liquid crystalline cholesterol-containing polymers. Doklady Academy Nauk USSR, 1976, 277, 1412-1415 (in Russ.).

8. Kitaigorodskii A.I. Molecular crystals: monograph. Moscow, Nauka, 1971. 424 p.

9. Shibaev V.P., Talrose R.V., Petrukhin B.S., Plate N.A. Liquid Crystalline poly-decylacrylate gels. Vysokomol. Soed., B series, 1971, 13, 4-5 (in Russ.).

10. Платэ Н. А., Шибаев В. П. Гребнеобразные полимеры и жидкие кристаллы. М.: Химия, 1980. 304 с. (a); Plate N.A., Shibaev V.P. Comb-shaped polymers and liquid crystals. Plenum Press, New-York, 1987. 415 p. (b).

11. Shibaev V.P. Comb-shaped liquid crystal polymers. Liquid Crystalline Polymers / ed. by N.A. Plate. Plenum Press, New York, London, 1993, 193-250. 
12. Finkelmann H., Ringsdorf H., Wendorff J. Model consideration and examples of enantiotropic liquid crystalline polymers. Makromol. Chem., 1978, 179, 273-276.

13. Finkelmann H., Ringsdorf H., Siol W., Wendorff J. Enantiotropic liquid crystalline polymer synthesis and models. ACS Symphosium Ser., 1978, 74, 22-32.

14. Shibaev V.P., Plate N.A., Freidzon Ya.S. Thermotropic cholesterol-containing liquid crystalline polymers. ACS Symposium Ser., 1978, 74, 33-55.

DOI: $10.1021 / \mathrm{bk}-1978-0074 . c h 004$.

15. Slukin T., Dunmur D., Stegemeyer H. Classic papers from the history of liquid crystals. Crystals that flow, Taylor and Francis Routledge, 2004. 512 p.

DOI: $10.1201 / 9780203022658$.

16. Blumstein A., Hsu E. Liquid crystalline order in polymers with mesogenic side groups. Liquid Crystalline Order in Polymers / ed. by A. Blumstein. Academic Press, New York, 1978, chapter 3, 105-140.

17. Clough S., Blumstein A., de Vries A. X-Ray Diffraction from polymers with mesomorphic order. Mesomorphic Order in Polymers / ed. by A. Blumstein. ACS Symposium series. Washington, D.S, Am. Chem. Soc., 1978, 74, chapter 1, 1-11.

DOI: $10.1021 /$ bk-1978-0074.ch001.

18. Strzelcki L., Liebert L., Keller P. Synthesis and polymerization of mesomorphes monomers. Bull. Soc. Chim., France, 1973, 597, 605-608.

19. Cser F., Nyitrai K., Hardy G. Polymerization in liquid crystalline state: monomer-polymer interactions. Mesomorphic Order in Polymers / ed. by A. Blumstein. ACS Symposium series. Washington, D.S, Am. Chem. Soc., 1978, 74, chapter 8, 95-107.

DOI: $10.1021 / \mathrm{bk}-1978-0074 . c h 008$.

20. Amerik Y., Krenzel B. Chemistry of liquid crystals and mesomorphic polymer systems. Moscow: Nauka, 1981. 288 p. (in Russ.).

21. International conference on liquid crystal polymers. France, Bordeaux, 20-24 July, 1987.

22. Shibaev V.P. Some new physico-chemical aspects of side chain LC polymers. Mol. Cryst. Liq. Cryst., 1994, 243, 201-230.

23. Side chain liquid crystal polymers / ed. by C.B. McArdle. Blackie and Son Ltd, Glasgow-London, 1989, 357 p. (a); Comb-shaped liquid crystals polymers with mesogenic side groups / ed. by V. Shibaev. Moscow, Mir, 1992, 568 p. (in Russ.) (b).

24. Sonin A.S. Liquid crystals: the first one hundred years. 2015, book 2, 408 p.

25. Shibaev V.P., Finkelmann H., Kharitonov A.V., Portugall M., Plate N.A., Ringsdorf H. Liquid crystalline cholesteric copolymers. Vysokomol. Soed., 1982, A23, 919. (in Russ.).

26. Shibaev V.P. Bobrovsky A.Yu., Boiko N.I. Photoactive liquid crystalline polymer systems with light- controllable structure and optical properties. Progress in Polym. Sci., 2003, 28 (5), 729-836.

27. Shibaev V.P. Liquid crystalline polymers. Reference module in materials science and materials engineering / ed. by S. Hashmi. Oxford: Elsevier, 2016, 1-46.

DOI: 10.1016/B978-0-12-803581-8.01301-1.

28. Ryabchun A.V., Bobrovsky A.Yu. Shibaev V.P. Photoinduced reorientation processes in thin films of photochromic LC polymers on substrates with a photocontrollable command surface. Polym. Sci. Ser. A, 2010, 52, 812-823.

DOI: $10.1134 / \mathrm{S} 0965545 \mathrm{X} 10080079$.

29. Shibaev V.P., Bobrovsky A.Yu. Liquid crystalline polymers: development trends and photocantrollable materials. Russ. Chem. Rev. Moscow, 2017, 86 (11), 1024-1072. DOI: $10.1070 /$ RCR4747.

30. Russian Patent № 2006133954. Method of making a photoluminescent security agent for verifying the authenticity of documents / Karasev A., Shibaev V., Ryabchun A., Bobrovsky A., Smirnov A.; publ. 2006; Right holder: NGO Kripten.

31. Sinitsyna O., Bobrovsky A., Meshkov G., Yaminsky I., Shibaev V. Direct observation of changes in focal conic domains of cholesteric films induced by ultraviolet irradiation. J. Phys. Chem. B, 2017, 121 (21), 54075412.

32. Bobrovsky A., Mochalov K., Solovyeva D., Shibaev V., Cigl M., Hamplova V., Bubnov A. Laser-induced formation of "craters" and "hills" in azobenzenecontaining polymethacrylate films. Soft Matter, 2020, 16 (23), 5398-5405.

DOI: $10.1039 / \mathrm{D} 0 \mathrm{SM} 00601 \mathrm{G}$.

33. Balenko N.V., Shibaev V.P., Bobrovsky A.Yu. Photoand mechano-sensitive composites on the base of liquid crystals dispered in elastic polymer matrices. Abstracts of 8th All Russia Kargin Conference «Polymer-2020». Tver, 9-13 November 2020, 431 (in Russ.).

34. Bugakov M., Boiko N., Abramchuk S., Zhu X., Shibaev V. Azobenzene-containing liquid crystalline block copolymer supramolecular complexes as a platform for photopatternable colorless materials. J. Mater. Chem. C, 2020, 8 (4), 1225-1230. DOI: 10.1039/C9TC06397H.

35. Bugakov M., Abdullaeva S., Samokhvalov P., Abramchuk S., Shibaev V., Boiko N. Hybrid fluorescent liquid crystalline composites: directed assembly of quantum dots in liquid crystalline block copolymer matrices. $R S C A d v$., 2020, 10 (26), 15264-15273.

DOI: $10.1039 / \mathrm{D} 0 \mathrm{RA} 02442 \mathrm{~B}$.

Поступила 10.11.2021, одобрена 29.11.2021, принята 8.12.2021 Received 10.11.2021, approved 29.11.2021, accepted 8.12.2021 